\title{
Effect of breast feeding on intelligence in children: prospective study, sibling pairs analysis, and meta-analysis
}

\author{
Geoff Der, G David Batty, Ian J Deary
}

\begin{abstract}
Objective To assess the importance of maternal intelligence, and the effect of controlling for it and other important confounders, in the link between breast feeding and children's intelligence.

Design Examination of the effect of breast feeding on cognitive ability and the impact of a range of potential confounders, in particular maternal IQ, within a national database. Additional analyses compared pairs of siblings from the sample who were and were not breast fed. The results are considered in the context of other studies that have also controlled for parental intelligence via meta-analysis.

Setting 1979 US national longitudinal survey of youth. Subjects Data on 5475 children, the offspring of 3161 mothers in the longitudinal survey.

Main outcome measure IQ in children measured by Peabody individual achievement test.

Results The mother's IQ was more highly predictive of breastfeeding status than were her race, education, age, poverty status, smoking, the home environment, or the child's birth weight or birth order. One standard deviation advantage in maternal IQ more than doubled the odds of breast feeding. Before adjustment, breast feeding was associated with an increase of around 4 points in mental ability. Adjustment for maternal intelligence accounted for most of this effect. When fully adjusted for a range of relevant confounders, the effect was small (0.52) and non-significant (95\% confidence interval -0.19 to 1.23$)$. The results of the sibling comparisons and meta-analysis corroborated these findings.

Conclusions Breast feeding has little or no effect on intelligence in children. While breast feeding has many advantages for the child and mother, enhancement of the child's intelligence is unlikely to be among them.
\end{abstract}

\section{Introduction}

Since 1929 many studies have examined the link between breast feeding and intelligence, most finding higher IQ scores among children who were breast fed. ${ }^{1}$ The few randomised controlled trials were confined to preterm infants, ${ }^{2-4}$ whereas studies of individuals born at term were observational in design. Inference from the observational studies is hampered by confounding: there are fundamental differences between mothers who choose to breast feed and those who do not. Studies that do not control adequately for confounders may mistake residual confounding for a real effect of breast feeding.

Many potential confounding variables have been identified, including duration of breast feeding, sex, maternal history of smoking, maternal age, maternal intelligence, maternal education, maternal training, paternal education, race or ethnicity, socioeconomic status, family size, birth order, birth weight, gestational age, and childhood experiences. ${ }^{5}$ Those singled out as particularly important include socioeconomic status, maternal education, and birth weight ${ }^{6}$ or socioeconomic status/parental education and stimulation of the child. ${ }^{7}$ In contrast, maternal intelligence is relatively overlooked as a potential confounder. This is surprising given the heritability of intelligence ${ }^{8}$ and the known association of maternal intelligence with both the initiation and duration of breast feeding. ${ }^{9}$

We examined the relation between breast feeding and intelligence and assessed the role of maternal IQ and other covariates in generating the association. We took both a conventional approach to control for confounders and an alternative approach using sibling comparison analysis. Used recently to assess the benefits of breast feeding, ${ }^{10}$ this approach has the considerable advantage of controlling for many confounding factors without having to measure them. Any factor that is the same for both members of a pair of siblings is automatically and fully controlled for. Thus, the method implicitly controls for parental intelligence.

\section{Methods}

We used data from the US national longitudinal survey of youth 1979 (NLSY79). ${ }^{11}$ This is a population based sample of 12686 young people ( 6283 female) aged 14 to 22 when first interviewed in 1979 who were then interviewed annually until 1994 and biennially thereafter. Since 1986 the children of the women in the survey have also been assessed biennially. The database for the children is referred to as the NLSY79 child and young adult sample ("young adult" because some of the children are now of adult age). ${ }^{12}$ As preterm babies are known to have different nutritional needs ${ }^{13}$ we excluded children born before the 35th week and those who weighed less than $2500 \mathrm{~g}$ at birth. We also excluded those born before 1979, when the survey began.

\section{Measures}

Children's cognitive ability-The Peabody individual achievement test (PIAT) was administered to children between the ages of 5 and 14 biennially from 1986 to 2002. Children were tested repeatedly if they fell within the age range in test years. We used the PIAT total scores, as well as the individual component scores for mathematics, reading comprehension, and reading recognition. To aid comparison of effect sizes across measures and with the results of other studies, we standardised all outcomes to a mean of 100 and standard deviation of 15 . 
Breast feeding-Women who had had a child since the previous interview were asked whether they breast fed the child at all and, if so, how old the child was when they stopped breast feeding. In most cases this information would have been obtained within a year of the birth. Even so, reports on duration of breast feeding were probably less reliable than reports of whether a child was breast fed or not.

Control variables-We chose control variables on the basis of associations with breast feeding or childhood cognitive development in the survey, ${ }^{14}{ }^{15}$ other studies of breast feeding and cognitive development, ${ }^{9}{ }^{16} 17$ and the most recent reviews of the subject. ${ }^{5-7} 18$

Child's environment-The short form of the home observation for measurement of the environment scale (HOME-SF ${ }^{19}$ was completed at each assessment, and we used the cognitive stimulation and emotional support subscales.

Child demographics-Sex, age, gestation (weeks), birth weight, and birth order were also used in the models.

Maternal characteristics-Maternal cognitive ability was measured with the armed forces qualification test (AFQT). ${ }^{11}$ This is derived from the arithmetic reasoning, word knowledge, paragraph comprehension, and mathematical knowledge sections of the Armed Services vocational aptitude battery. It was administered in 1980. Level of education was classified as the highest grade completed by the mother at the time of the child's birth. Race was classified as Hispanic, black, or non-Hispanic/ non-black. The latter includes white people and others who did not identify themselves as black or Hispanic. Poverty status indicates whether the household income was below the poverty threshold at the birth of the child. We also included the mother's age at the birth of the child plus a binary variable to indicate whether the mother smoked during the pregnancy.

\section{Statistical analysis}

Linkage of the data from the survey with the child and young adult sample resulted in a dataset that contained one or more assessments for each child and one or more children per mother. This can be viewed as a hierarchical structure of assessments nested within children and children nested within mothers. The multiple assessments made on each child are unlikely to be statistically independent, nor are the data for siblings. To accommodate this lack of independence we used random effects models, which have the advantage of being able to use all available assessments for each child and all children, whether they are siblings or not. The statistical background for this use of random effects models is given elsewhere, ${ }^{2021}$ and tutorial articles showing analyses similar to those conducted here are also available. ${ }^{22-25}$

All analyses were carried out separately for PIAT total score and the three subscales: mathematics, reading recognition, and reading comprehension. Initial analysis assessed the association between each of the potential confounders and breast feeding. The main analyses estimated the effect of breast feeding on cognitive ability; examined the extent to which each of the confounders, individually, attenuated the effect; and then examined the attenuation of multiple confounders.

To use the random effects models we structured data so that each occasion when measurements were done was a separate record in the data file. Each child then has one or more records depending on the number of PIAT assessments completed. Data that were not assessed repeatedly, or do not change with time, were attached to this record, including, for example, information about the mother, the pregnancy, and the child's birth. Each record was also indexed with some time or occasion variable. We used the child's age at the time of the assessment, centred at 10 years. To control for the correlation between repeated measures and between siblings, the models included random intercepts, random slopes in age (the child's), and intercept-slope covariance, both at the child level and at the level of the mother. Thus there were six random effects in each of the models. All models also included a fixed effect of child's age. The models were estimated by restricted maximum likelihood with proc mixed in SAS version 9.1.

As the sample contained a large number of siblings, it was also well suited to examining the same question with sibling comparison analysis. A simple test of the null hypothesis of no effect of breast feeding can be made by identifying pairs of siblings in which one sibling was breast fed and the other was not, subtracting the PIAT scores of the sibling who was not breast fed from those of the one who was, and testing whether the resulting differences have a mean of zero. The same can be done for sibling pairs that are discordant for duration of breast feeding, subtracting the scores of the sibling with the shorter duration of breast feeding.

We considered the results of both types of analysis in the context of other comparable studies via meta-analysis (comprehensive meta-analysis program version 2.2.020, www.metaanalysis.com). There are no agreed standards of study quality in this area, and the four recent reviews identified all used different criteria, resulting in sets of studies with relatively little overlap..$^{5-7}{ }^{18}$ We included only studies that quantified the effect of breastfeeding status on cognitive ability after controlling for parental intelligence among full term infants. We searched Medline (1966 to January 2006), ISI Web of Knowledge, and the British Library's electronic table of contents for any combination of "breast feeding/breast milk/infant feeding" and "cognitive development/intelligence/intellectual development" and supplemented the results with additional studies identified from the reference lists of the four reviews mentioned and from those of individual studies.

\section{Results}

Table 1 shows descriptive statistics for the potential confounders, broken down by breastfeeding status. The association of each of them with breastfeeding status is shown as an odds ratio. Children who were breast fed had mothers with higher IQ and with more education and who were older, less likely to be in poverty or to smoke, and more likely to provide a more stimulating and supportive home environment. Hispanic mothers were less likely to breast feed their children and black mothers much less likely. The children who were breast fed were likely to be heavier at birth and earlier in birth order, although this could be a reflection of family size. There was no difference in gestation or the proportion of male infants who were breast fed.

A one standard deviation advantage in mother's IQ more than doubled of the odds of breast feeding. Mother's education had a similar but slightly weaker effect. As gestation and sex were not significantly associated with breast feeding, they were not included in the remaining analyses. For the analyses of PIAT scores we had full data on 16744 assessments of 5475 children born to 3161 mothers.

Table 2 shows the effect of breast feeding on the cognitive outcomes, both unadjusted and adjusted individually for each of the confounders. Each row gives the effect of breast feeding on the outcome as a regression coefficient (B) with its standard error and $\mathrm{P}$ value, adjusted for the confounder listed. The attenuation of the effect size is shown as a percentage of the 
Table 1 Association of potential confounders with breast feeding

\begin{tabular}{|c|c|c|c|c|c|c|}
\hline \multirow{2}{*}{ Confounder } & \multicolumn{2}{|c|}{ Not breast fed } & \multicolumn{2}{|c|}{ Breast fed } & \multirow{2}{*}{$\begin{array}{c}\text { Odds ratio* }(95 \% \text { confidence } \\
\text { interval) }\end{array}$} & \multirow{2}{*}{$P$ value } \\
\hline & Mean (SD) or \% & No & Mean (SD) or \% & No & & \\
\hline Mother's AFQT score & 26.24 (22.33) & 3001 & $46.44(27.76)$ & 2701 & 2.30 (2.16 to 2.44) & $<0.001$ \\
\hline Mother's education & $11.50(2.14)$ & 3119 & $12.79(2.48)$ & 2819 & 1.83 (1.73 to 1.95) & $<0.001$ \\
\hline Mother's age & $23.83(4.50)$ & 3125 & $25.79(4.64)$ & 2823 & 1.55 (1.47 to 1.64) & $<0.001$ \\
\hline HOME cognitive stimulation & $94.09(16.62)$ & 2844 & $101.00(14.26)$ & 2620 & 1.59 (1.50 to 1.69) & $<0.001$ \\
\hline HOME emotional support & 95.18 (16.54) & 2791 & 100.67 (14.45) & 2601 & 1.44 (1.36 to 1.52) & $<0.001$ \\
\hline Gestation (weeks) & $39.05(1.58)$ & 3125 & $39.01(1.55)$ & 2823 & 0.97 (0.93 to 1.03) & 0.315 \\
\hline Birth weight $(\mathrm{g})$ & $3390(47)$ & 3125 & $3470(47)$ & 2823 & 1.21 (1.15 to 1.27) & $<0.001$ \\
\hline Birth order & $1.97(1.07)$ & 3125 & $1.85(1.02)$ & 2823 & 0.90 (0.85 to 0.94$)$ & $<0.001$ \\
\hline Family in poverty $\dagger$ & $36.4 \%$ & 3108 & $15.8 \%$ & 2817 & 0.33 (0.29 to 0.37) & $<0.001$ \\
\hline Mother smoked in pregnancy† & $35.7 \%$ & 3120 & $25.6 \%$ & 2816 & 0.62 (0.55 to 0.69$)$ & $<0.001$ \\
\hline Male infant† & $51.7 \%$ & 3125 & $50.6 \%$ & 2823 & 0.96 (0.87 to 1.06) & 0.413 \\
\hline Hispanicł & $49.4 \%$ & 615 & $50.6 \%$ & 630 & 0.72 (0.63 to 0.82$)$ & $<0.001$ \\
\hline Black $\ddagger$ & $74.9 \%$ & 1264 & $25.1 \%$ & 423 & 0.24 (0.21 to 0.27$)$ & $<0.001$ \\
\hline Not black/Hispanicł & $41.3 \%$ & 1246 & $58.7 \%$ & 1770 & 1.00 & \\
\hline
\end{tabular}

AFQT=armed forces qualification test; HOME=home observation of the environment.

${ }^{*}$ Odds ratios for breast feeding are per 1 SD of mother's AFTQ score, education, age, HOME scores, gestation, and birth weight.

†Reference groups are family not in poverty, mother did not smoke in pregnancy, female.

$\ddagger$ Row percentage.

unadjusted figure. The unadjusted effects of breast feeding correspond to an advantage for those breast fed of 4.1 to 4.7. These are comparable with effects reported in other studies. ${ }^{5}$ Adjustment for mother's IQ reduced this advantage by $71 \%$ to $75 \%$, and adjustment for mother's education by $34 \%$ to $42 \%$. Family poverty, maternal race, maternal age, and HOME stimulation score were important confounders.

Table 3 shows the results of including all the confounders simultaneously. In this case, each row of the table gives the effect of the confounder on the outcome, adjusted for all the others and for the child's age at assessment. The fully adjusted effect of breast feeding averages slightly less than half a point with a range of 0.36 to 0.52 . These are small effects, and none is significant even with the large numbers in these analyses. Maternal IQ has the largest independent effect, with maternal education, age, family poverty, HOME stimulation score, and birth order all making independent contributions for most outcomes.

To simulate a study without adjustment for maternal intelligence, but which was otherwise well controlled, we re-ran the models in table 3 omitting maternal IQ. The effects of breast feeding were then at least double those shown in table 3 and all were significant (table 4). Although these effects were still small, they do show that omitting maternal intelligence can seriously overestimate the effect of breast feeding.

Because observational studies use dose-response relation to infer causality ${ }^{26}$ we repeated the analysis including data only on those who were breast fed and introducing duration of breast feeding in months (defined as four weeks) to the model (table 4). Although the effects for reading comprehension and PIAT total score were significant, all effects were small considering that the median duration of breast feeding is three months and the 95th centile is 14 months. We repeated the analysis dividing those breast fed into quarters of duration of breast feeding and contrasted each of these with those not breast fed (table 4). The results broadly concur with the previous analysis. There were significant differences for the PIAT total score and the maths and reading comprehension subscales, but only for those in the top quarter of duration of breast feeding. There were also some signs of a departure from linearity in the second quarter.

\section{Sibling pairs analysis}

There were 332 sibling pairs discordant for breastfeeding status and 545 discordant for duration of breast feeding. Table 5 shows the mean differences between both groups of siblings for PIAT

Table 2 Effect of breast feeding on cognitive outcomes, unadjusted and adjusted singly for each confounder, in 3161 mothers, 5475 children, and 16744 assessments. All significant at $\mathrm{P}<0.001$ except where marked

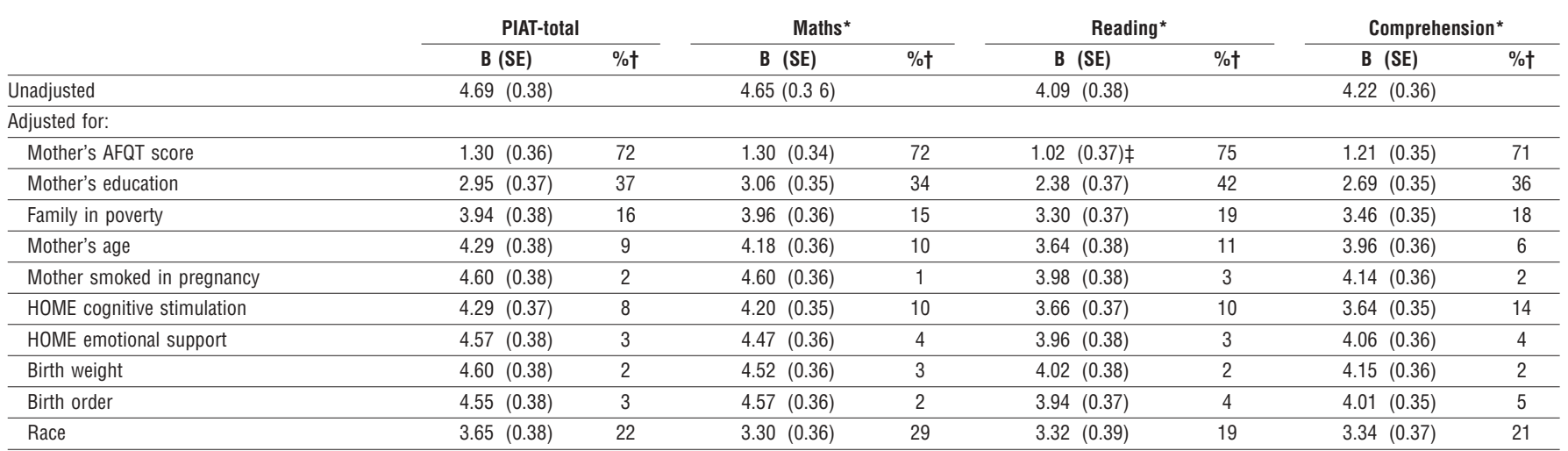

PIAT=Peabody individual achievement test; AFQT=armed forces qualification test; HOME=home observation for measurement of the environment.

*Individual components of PIAT.

$\dagger$ Percentage of unadjusted figure.

$\ddagger P=0.006$ 
Table 3 Mutually adjusted effects of breast feeding and confounders on cognitive outcomes in 3161 mothers, 5475 children, and 16744 assessments

\begin{tabular}{|c|c|c|c|c|c|c|c|c|}
\hline \multirow{2}{*}{ Confounder } & \multicolumn{2}{|c|}{ PIAT-total } & \multicolumn{2}{|c|}{ Maths* } & \multicolumn{2}{|c|}{ Reading* } & \multicolumn{2}{|c|}{ Comprehension* } \\
\hline & B (SE) & $P$ & B (SE) & $\mathbf{P}$ & B (SE) & $\mathbf{P}$ & B (SE) & $\mathbf{P}$ \\
\hline Breast feeding & $0.52(0.36)$ & 0.149 & $0.52(0.34)$ & 0.130 & $0.36(0.37)$ & 0.332 & $0.52(0.35)$ & 0.134 \\
\hline Mother's AFQT score & $4.43(0.26)$ & $<0.001$ & $3.87(0.25)$ & $<0.001$ & $3.77(0.27)$ & $<0.001$ & $3.97(0.25)$ & $<0.001$ \\
\hline Family in poverty & $-1.72(0.41)$ & $<0.001$ & $-0.98(0.39)$ & 0.012 & $-1.70(0.42)$ & $<0.001$ & $-1.82(0.39)$ & $<0.001$ \\
\hline Mother's age & $0.98(0.20)$ & $<0.001$ & $0.72(0.19)$ & $<0.001$ & $1.05(0.20)$ & $<0.001$ & $0.69(0.19)$ & $<0.001$ \\
\hline Mother smoked in pregnancy & $0.08(0.38)$ & 0.839 & $0.37(0.36)$ & 0.305 & $-0.11(0.39)$ & 0.771 & $0.14(0.36)$ & 0.694 \\
\hline HOME emotional support & $0.17(0.09)$ & 0.072 & $0.25(0.11)$ & 0.020 & $0.15(0.10)$ & 0.120 & $0.14(0.11)$ & 0.200 \\
\hline Birth weight & $0.32(0.16)$ & 0.047 & $0.40(0.15)$ & 0.010 & $0.20(0.17)$ & 0.234 & $0.25(0.16)$ & 0.113 \\
\hline Birth order & $-1.54(0.18)$ & $<0.001$ & $-0.79(0.17)$ & $<0.001$ & $-1.47(0.19)$ & $<0.001$ & $-1.69(0.18)$ & $<0.001$ \\
\hline Hispanic & $-0.36(0.52)$ & 0.494 & $-1.85(0.49)$ & $<0.001$ & $0.33(0.53)$ & 0.534 & $0.48 \quad(0.49)$ & 0.329 \\
\hline Black & $-0.90(0.50)$ & 0.074 & $-2.79(0.47)$ & $<0.001$ & $0.54(0.52)$ & 0.299 & $-0.03(0.48)$ & 0.950 \\
\hline
\end{tabular}

PIAT=Peabody individual achievement test; AFQT=armed forces qualification test; HOME=home observation for measurement of the environment.

*Individual components of PIAT.

scores. None of them was significantly different from zero. In both cases, we also tested for any differences between the sibling pairs in the confounding factors used in the earlier analysis. None was significant (results not shown), suggesting that the method controls for all those factors and there is no need for further analysis. In short, the sibling pairs analysis concurs with the earlier analysis in offering no support for a cognitive advantage of breast feeding once confounding is taken into account.

\section{Meta-analysis}

Our search yielded 431 references, 73 of which reported original data for full term infants. In 19 reports the analysis explicitly controlled for parental IQ and in one further report ${ }^{10}$ it implicitly controlled for parental IQ via sibling comparisons. The 19 reports used data from 12 studies because studies that followed children prospectively and assessed them at different ages often repeated the analysis and published the results separately. When the published results did not present the data in a comparable format, we approached the corresponding author directly.

The figure summarises eight of the 12 studies, ${ }^{27-34}$ together with the results for PIAT total score from our study. We excluded four studies because the data were no longer available in a suit- able form, "nearly 100\% had some breast feeding" "T6 (T Vik, personal communication), or we could not contact the authors. ${ }^{37}$ When a study assessed children at more than one age we chose the oldest age available as childhood measures of cognitive ability increase in reliability with age. ${ }^{39}$ When more than one measure of ability was assessed we took the more general measure.

The studies with the biggest IQ advantage for breast feeding were those with smaller sample sizes and that controlled for fewer of the important additional confounders-namely, socioeconomic status, maternal education, maternal age, and HOME score. The study with the largest effect had a sample that was socially heterogeneous (D Hay, personal communication) and the next largest one that was "disadvantaged, consisting almost exclusively of members of social classes IV and V:" ${ }^{32}$ Two studies assessed the children at only 2 years of age when the available measures are "best characterized as indices of mental development, and not IQ."

The greatest support for an effect of breast feeding came from the study by Fergusson et al, ${ }^{27}$ which was based on the previous largest sample and from a birth cohort with an outstanding follow-up rate. It did not, however, control for maternal age,

Table 4 Supplementary analysis: omitting mother's $I Q$, and duration of breast feeding (only in those breast fed)

\begin{tabular}{|c|c|c|c|c|c|c|c|c|}
\hline & \multicolumn{2}{|c|}{ PIAT-total } & \multicolumn{2}{|c|}{ Maths* } & \multicolumn{2}{|c|}{ Reading* } & \multicolumn{2}{|c|}{ Comprehension* } \\
\hline & B (SE) & $P$ value & B (SE) & $P$ value & B (SE) & $P$ value & B (SE) & $P$ value \\
\hline Breast feeding $\dagger$ & $1.42(0.37)$ & $<0.001$ & $1.33(0.35)$ & $<0.001$ & $1.14(0.38)$ & 0.002 & $1.32(0.35)$ & $<0.001$ \\
\hline \multicolumn{9}{|c|}{ Duration of breast feeding } \\
\hline Not breast fed & 0.00 & & 0.00 & & 0.00 & & 0.00 & \\
\hline 1-5 weeks & $0.32(0.51)$ & 0.526 & $0.04(0.49)$ & 0.934 & $0.33(0.53)$ & 0.533 & $0.47(0.49)$ & 0.334 \\
\hline 6-12 weeks & $0.18(0.52)$ & 0.734 & $0.32(0.50)$ & 0.514 & $0.01 \quad(0.54)$ & 0.980 & $0.21 \quad(0.50)$ & 0.681 \\
\hline$\geq 29$ weeks & $1.50(0.59)$ & 0.011 & $1.41(0.56)$ & 0.012 & $1.00(0.61)$ & 0.099 & $1.72(0.57)$ & 0.002 \\
\hline
\end{tabular}

PIAT=Peabody individual achievement test.

*Individual components of PIAT.

†Mutually adjusted model as in table 3 , but omitting mother's AFQT score.

łDuration of breast feeding (in months) as a continuous predictor; 1587 mothers, 2454 children, 7416 assessments.

Table 5 Supplementary analysis-sibling pairs

\begin{tabular}{|c|c|c|c|c|c|c|c|c|}
\hline \multirow{2}{*}{ Breast feeding } & \multicolumn{2}{|c|}{ PIAT-total } & \multicolumn{2}{|c|}{ Maths* } & \multicolumn{2}{|c|}{ Reading* } & \multicolumn{2}{|c|}{ Comprehension* } \\
\hline & Difference (SE) & $P$ value & Difference (SE) & $P$ value & Difference (SE) & $P$ value & Difference (SE) & $P$ value \\
\hline Status $†$ & $-0.63(0.94)$ & 0.506 & $0.02(1.01)$ & 0.984 & $-1.00(0.96)$ & 0.296 & $-0.54(1.00)$ & 0.589 \\
\hline Duration $\ddagger$ & $-0.13(0.76)$ & 0.866 & $-0.11(0.82)$ & 0.890 & $-0.41(0.79)$ & 0.602 & $0.20(0.79)$ & 0.796 \\
\hline
\end{tabular}

PIAT=Peabody individual achievement test.

*Individual components of PIAT.

†Breastfed sibling minus non-breastfed sibling; $n=332$ pairs.

$\ddagger$ Sibling with longer duration minus sibling with shorter duration ( $n=545$ pairs). 
smoking, or the HOME score, and its measure of maternal education contained only the three categories: secondary education only; secondary school qualification; tertiary qualification. The study therefore may not have been adequately controlled, as the authors themselves acknowledge in their conclusion.

In the figure we have ordered the studies by decreasing standard error, and the asymmetric pattern of the effect estimates suggests publication bias. There is significant heterogeneity in their estimates of the effect of breast feeding $(Q=21.07$, $\mathrm{df}=8, \mathrm{P}=0.007$ ), which is unsurprising given the minimal criteria for inclusion, the differences between the samples studied, and in particular the different numbers of additional covariates controlled for. This is consistent with the results from the longitudinal survey: maternal IQ explains most of the effect of breast feeding, but not all; other important confounders need to be taken into account. To adjust for this difference between studies we used the number of additional confounders in each study as a predictor of the effect of breast feeding in a meta-regression. Because this varies between studies but not within them it is a good candidate for meta-regression. ${ }^{40}$ Although a count is a somewhat simplistic summary measure, it did account for the heterogeneity (model $\mathrm{Q}=7.41, \mathrm{df}=1, \mathrm{P}=0.006$; residual $\mathrm{Q}=13.66$, $\mathrm{df}=7, \mathrm{P}=0.058$ ). The estimates (standard errors) were: intercept $3.37(0.84)$; slope $-0.40(0.15)$, which equates to an IQ advantage of 3.37 points in a study controlling for IQ but no other confounders, and 0.16 of a point for a study with IQ and all eight additional confounders. With full control for covariates there is effectively no advantage to breast feeding. This result is not entirely due to the high weighting that this study has in the meta-regression; an unweighted meta-regression yielded an estimated advantage of breast feeding of -0.39 for a fully controlled study (that is, a slight disadvantage).

We analysed the results from the only other study to have used sibling comparisons ${ }^{10}$ separately and with the corresponding results from this study. (We used the method of Evenhouse and Reilly ${ }^{10}$ to obtain separate estimates for strict comparability.) The estimated standardised difference in means was 0.025 $(\mathrm{SE}=0.041, \mathrm{P}=0.540)$ for breastfeeding status and $0.040(0.036$, $\mathrm{P}=0.271)$ for duration of breast feeding. Thus, the evidence from the only two sibling pair studies to date, when taken together, offer no support for an advantage of breast feeding.

\section{Discussion}

Most of the observed association between breast feeding and cognitive development is the result of confounding by maternal intelligence. Level of cognitive stimulation at home, mother's educational attainment and age at the birth of the child, child's birth order, and family financial hardship all have independent effects. In fully adjusted analyses, the advantage of breast feeding was small and not significant.

Only a small proportion of the many studies that have shown a positive effect of breast feeding on children's cognitive ability control for maternal intelligence. By omitting this from the fully adjusted models, while leaving in maternal education and the other confounders, we have shown that maternal education is an imperfect surrogate. The effect sizes were at least double and were all significant. Studies that do not control for maternal intelligence will probably give biased results.

Comparison of the results of this study with others that controlled for maternal intelligence shows a pattern familiar in research synthesis, whereby the smaller studies with fewer controls display the largest effects. Our study was about five times the size of the largest previous study. ${ }^{27}$ Heterogeneity between studies can be accounted for by the number of additional controls. The results lend little support to the hypothesis that breast feeding promotes intelligence in full term infants.

The method of sibling comparisons is well suited to assessing the benefits of breast feeding. In particular, it automatically controls for any confounding factors that are the same for each of the siblings in a pair. Other potential confounders can be incorporated into the analysis by using the within pair differences as predictors of the within pair difference in outcome in an ordinary least squares linear model. The only previous study that has used the method to assess the benefits of breast feeding examined its relation to 15 indicators of physical health, emotional health, and cognitive ability. ${ }^{10}$ There were apparent benefits of breastfeeding status and duration for around two thirds of the outcomes. All except cognitive ability were non-significant in the sibling comparisons. They used a $10 \%$ level for significance, however, and, judged against the more conventional 5\% level, the effect for breastfeeding status was not significant and that for duration of breast feeding marginal. The results from the sibling comparisons in our study and the two

Summary of studies that controlled for maternal IQ and other confounders as indicated. IQ tests: GOS=Groningen developmental scale; HOME=home observation for measurement of the environment scale; MDI=Bayley mental development index; PIAT=Peabody individual achievement test; SC=sentence completion; SES=socioeconomic status; WISC=Weschler child intelligence scale 
studies combined provide no support for a beneficial effect of breast feeding.

\section{Wider application of results}

The generalisability of the results presented here must be considered carefully. This study and the others included in the meta-analysis are all based on samples from developed countries: United States ${ }^{10}{ }^{32}{ }^{41}$ Europe,${ }^{28}{ }^{30}{ }^{33}$ Australia, ${ }^{34}$ and New Zealand. ${ }^{27}$ Generalisation of the findings beyond these and similar societies would be unwise. We have also excluded premature and low birthweight infants for whom the effect may be different.

The broader context of breast feeding should also be considered. Evidence showing the many benefits of breast feeding for the child and mother led the World Health Organization and UNICEF to formulate the Innocenti Declaration, ${ }^{42}$ which includes exclusive breast feeding for 4-6 months as a global goal. Many of these benefits are equally applicable to developed countries. ${ }^{43}$ Even if it does not enhance intelligence, breast feeding remains "an unequalled way of providing ideal food for the healthy growth and development of infants."

We are grateful to Alex Ghys, Dale Hay, and Sandra Jacobson for providing data for the meta-analysis.

Contributors: The idea for the paper was generated during discussions between the authors. GD conducted the analysis, wrote the first draft of the manuscript, and is guarantor. All authors made substantial contributions to subsequent revisions.

Funding: GD is employed by the Medical Research Council. GDB is funded by a Wellcome advanced training fellowship and is also affiliated to the University of Edinburgh, Department of Psychology. ID is the recipient of a Royal Society-Wolfson research merit award.

Competing interests: None declared.

Ethical approval: Not required.

1 Hoefer C, Hardy M. Later development of breast fed and artificially fed infants. JAMA 1929;92:615-20.

2 Lucas A, Morley R, Cole TJ, Gore SM. A randomised multicentre study of human milk versus formula and later development in preterm infants. Arch Dis Child Fetal Neonatal Ed 1994;70:F141-6.

3 Lucas A, Morley R, Cole TJ, Lister G, Leeson-Payne C. Breast-milk and subsequen intelligence quotient in children born preterm. Lancet 1992;339:261-4

4 Morley R, Cole TJ, Powell R, Lucas A. Mother's choice to provide breast milk and developmental outcome. Arch Dis Child 1988;63:1382-5.

5 Anderson JW, Johnstone BM, Remley DT. Breast-feeding and cognitive development: a meta-analysis. Am J Clin Nutr 1999;70:525-35.

6 Drane DL, Logemann JA. A critical evaluation of the evidence on the association between type of infant feeding and cognitive development. Paediatr Perinat Epidemiol 2000;14:349-56.

7 Jain A, Concato J, Leventhal JM. How good is the evidence linking breastfeeding and intelligence? Pediatrics 2002;109:1044-53.

8 Bouchard T, McGue M. Genetic and environmental influences on human psychological differences. J Neurobiol 2003;54:4-45.

9 Silva PA, Buckfleld P, Spears GF. Some maternal and child developmental characteristics associated with breast feeding: a report from the Dunedin multidisciplinary child developmental study. Aust Paediatr J 1978;14:265-8.

\section{What is known already on this topic}

Breast feeding has many benefits for both child and mother

Breastfed children tend to score higher on intelligence tests

There are important differences between mothers who breast feed and those who do not

\section{What this study adds}

The apparent effect of breast feeding on intelligence in offspring is accounted for by characteristics of the mother and the home environment

The mother's own intelligence plays the largest part in this explanation
10 Evenhouse E, Reilly S. Improved estimates of the benefits of breastfeeding using sibling comparisons to reduce selection bias. Health Services Res 2005;40:1781-802.

1 Center for Human Resource Research. NLSY79 users guide. Columbus, OH: Ohio State University, 2004.

12 Center for Human Resource Research. NLSY79 child and young adult data users guide. Columbus, OH: Ohio State University, 2002.

13 Lucas A, Morley R, Cole TJ, Gore SM, Lucas PJ, Crowle P, et al. Early diet in preterm babies and developmental status at 18 months. Lancet 1990;335:1477-81.

14 Keck C. The initiation and duration of breastfeeding among employed women in the United States. Columbus, OH: Ohio State University, 1997 (PhD thesis).

15 Quo G, Harris KM. The mechanisms mediating the effects of poverty on children's intellectual development. Demography 2000;37:431-47.

16 Johnson DL, Swank PR, Howie VM, Baldwin CD, Owen M, Luttman D. Does HOME add to the prediction of child intelligence over and above SES? J Genetic Psychol $1993 ; 154: 33-40$

17 Pollock J. Long-term associations with infant feeding in a clinically advantaged population of babies. Dev Med Child Neurol 1994:36:429-40.

18 Rey J. Breastfeeding and cognitive development. Acta Paediatr Suppl 2003;92:11-8.

19 Caldwell BM, Bradley RH. Home observation for measurement of the environment. Little Rock, AR: University of Arkansas, 1984

20 Diggle PJ, Liang KL, Zeger SL. Analysis of longitudinal data. Oxford: Oxford University Press, 1994.

21 Goldstein H. Multilevel statistical models. 2nd ed. London: Arnold, 1995.

29 Baumler ER, Carvajal S, Harrist RB. Analysis of repeated measures data. In: Reise SP, Duan N, ed. Multilevel modeling: methodological advances, issues, and applications. Mahwah, NJ: Lawrence Erlbaum, 2003:140-56

23 Cnaan A, Laird NM, Slasor P. Using the general linear mixed model to analyse unbalanced repeated measures and longitudinal data. Stat Med 1997;16:2349-80.

24 Singer JD. Using SAS PROC MIXED to fit multilevel models, hierarchical models, and individual growth models. JEduc Behav Stat 1998:23:323-55.

25 Willett JB, Singer JD, Martin NC. The design and analysis of longitudinal studies of development and psychopathology in context: statistical models and methodological recommendations. Develop Psychopathol 1998;10:395-426.

26 Hill AB. Principles of medical statistics. New York: Oxford University Press, 1971

27 Fergusson DM, Beautrais AL, Silva PA. Breast-feeding and cognitive development in the first seven years of life. Soc Sci Med 1982;16:1705-8.

28 Ghys A, Bakker E, Hornstra G, van den Hout M. Red blood cell and plasma phospholipid arachidonic and docosahexaenoic acid levels at birth and cognitive development at 4 years of age. Early Hum Dev 2002;69:83-90

29 Gomez-Sanchiz M, Canete R, Rodero I, Baeza JE, Gonzalez JA. Influence of breast-feeding and parental intelligence on cognitive development in the 24-month-old child. Clin Pediatr (Phila) 2004;43:753-61.

30 Hay DF, Pawlby S, Sharp D, Asten P, Mills A, Kumar R. Intellectual problems shown by 11-year-old children whose mothers had postnatal depression. J Child Psychol Psychiatry 2001;42:871-89.

31 Jacobson SW, Chiodo LM, Jacobson JL. Breastfeeding effects on intelligence quotient in 4- and 11- year-old children. Pediatrics 1999;103:e71.

32 Morrow-Tlucak M, Haude RH, Ernhart CB. Breastfeeding and cognitive development in the first 2 years of life. Soc Sci Med 1988;26:635-9.

33 Richards M, Wadsworth M, Rahimi-Foroushani A, Hardy R, Kuh D, Paul A. Infant nutrition and cognitive development in the first offspring of a national UK birth cohort Dev Med Child Neurol 1998:40:163-7.

34 Wigg NR, Tong SL, McMichael AJ, Baghurst PA, Vimpani G, Roberts R. Does breastfeeding at six months predict cognitive development? Austr N Z J Public Health 1998;22:232-6.

35 Johnson DL, Swank PR, Howie VM, Baldwin CD, Owen M. Breast feeding and children's intelligence. Psychol Rep 1996;79:1179-85.

36 Angelsen NK, Vik T, Jacobsen G, Bakketeig LS. Breast feeding and cognitive development at age 1 and 5 years. Arch Dis Child 2001;85:183-8.

37 de Andraca I, Pino P, de la Parra A, Rivera F, Castillo M. [Risk factors for psychomotor development among infants born under optimal biological conditions]. Rev Saude Publica 1998;32:138-47.

38 Vreugdenhil HJ, Mulder PG, Emmen HH, Weisglas-Kuperus N. Effects of perinatal exposure to PCBs on neuropsychological functions in the Rotterdam cohort at 9 years of age. Neuropsychology 2004:18:185-93.

39 Wilson RS. The Louisville twin study: developmental synchronies in behavior. Child Dev 1983;54:298-316.

40 Thompson SG, Higgins JPT. How should meta-regression analyses be undertaken and interpreted? Stat Med 2002;21:1559-73.

41 Jacobson S, Jacobson J. Breastfeeding and intelligence. Lancet 1992;339:926.

$42 \mathrm{WHO} / \mathrm{UNICEF}$. The Innocenti declaration on the protection, promotion and support of breastfeeding: Geneva: WHO/UNICEF, 1990.

43 American Academy of Pediatrics. Policy statement. Breastfeeding and the use of human milk. Pediatrics 1997;100:1035-9.

44 Yngve A, Sjostrom M. Breastfeeding in countries of the European Union and EFTA: current and proposed recommendations, rationale, prevalence, duration and trends. Public Health Nutr 2001;4:631-45.

45 World Health Organization. Global strategy for infant and young child feeding. Geneva: WHO, 2000.

(Accepted 30 August 2006)

doi $10.1136 /$ bmj.38978.699583.55

MRC Social and Public Health Sciences Unit, Glasgow G12 8RZ

Geoff Der statistician

G David Batty Wellcome fellow

Department of Psychology, University of Edinburgh, Edinburgh

Ian J Deary professor of differential psychology

Correspondence to: G Der Geoff@msoc.mrc.gla.ac.uk 